San Jose State University

SJSU ScholarWorks

$5-1-2007$

\title{
Cultural Self-Efficacy of Graduating Baccalaureate Nursing Students in a State Funded University in the Silicon Valley
}

Lihua Liu

San Jose State University

Follow this and additional works at: https://scholarworks.sjsu.edu/etd_projects

Part of the Other Nursing Commons

\section{Recommended Citation}

Liu, Lihua, "Cultural Self-Efficacy of Graduating Baccalaureate Nursing Students in a State Funded University in the Silicon Valley" (2007). Master's Projects. 781.

DOI: https://doi.org/10.31979/etd.n6t4-nu9b

https://scholarworks.sjsu.edu/etd_projects/781

This Master's Project is brought to you for free and open access by the Master's Theses and Graduate Research at SJSU ScholarWorks. It has been accepted for inclusion in Master's Projects by an authorized administrator of SJSU ScholarWorks. For more information, please contact scholarworks@sjsu.edu. 


\section{SAN JOSE STATE UNIVERSITY \\ SCHOOL OF NURSING}

\section{MÁSTER'S PROGRAM PROJECT OPTION (PLAN B) PROJECT SIGNATURE FORM}

STUDENT NAME

LIHUA LIU

SEMESTER ENROLLED Spring 2007

TITLE OF PROJECT

cuctural self-efficacy of Graduating Baccalaureate Nursing students

Silicon Valley

The project and manuscript have been successfully completed and meet the standards of the School of Nursing at San Jose State University. The project demonstrates the application of professional knowledge, clinical expertise, and scholarly thinking. An abstract of the project and two copies of the manuscript are attached.

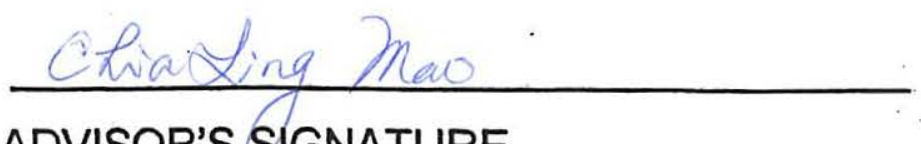

ADVISOR'S SIGNATURE

LruEllen A. Bannes willis

ADVISOR'S SIGNATURE

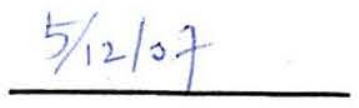

DATE

Please submit this form to the Graduate Coordinator. Attach abstract, two copies of the manuscript, and documentation of submission to the journal (i.e., postal receipt). 
Cultural Self-Efficacy of Graduating Baccalaureate Nursing Students in a State Funded University in the Silicon Valley

By Lihua Liu, Dr. Chia-Ling Mao, and Dr. Lou Ellen Barnes-Willis

\begin{abstract}
The purpose of the study was to examine the level of cultural self-efficacy of graduating baccalaureate nursing students, who care for diverse populations, in a state funded university in the Silicon Valley, California. The level of cultural self-efficacy was measured using Bernal and Froman's Cultural Self-Efficacy Scale (CSES). A convenience sample of 48 nursing students completed an 8-item demographic questionnaire and a 26-item CSES. The subjects of this study were found to have an increased level of cultural confidence in comparison with previous studies. This study suggests nurse educators continue to incorporate cultural concepts and skills in the nursing curriculum.
\end{abstract}


Running head: CULTURAL SELF-EFFICACY

\author{
Cultural Self-Efficacy of Graduating Baccalaureate Nursing Students \\ in a State Funded University in the Silicon Valley \\ Lihua Liu, MS, RN, Lecturer \\ Chia-Ling Mao, PhD, RN, Associate Professor \\ Lou Ellen A. Barnes-Willis, DNSc, RN, Lecturer \\ School of Nursing \\ San Jose State University, California
}




\begin{abstract}
The purpose of the study was to examine the level of cultural self-efficacy of graduating baccalaureate nursing students, who care for diverse populations, in a state funded university in the Silicon Valley, California. The level of cultural self-efficacy was measured using Bernal and Froman's Cultural Self-Efficacy Scale (CSES). A convenience sample of 48 nursing students completed an 8-item demographic questionnaire and a 26-item CSES. The subjects of this study were found to have an increased level of cultural confidence in comparison with previous studies. This study suggests nurse educators continue to incorporate cultural concepts and skills in the nursing curriculum.
\end{abstract}




\section{Cultural Self-Efficacy of Graduating Baccalaureate Nursing Students in a State Funded University in the Silicon Valley \\ Background}

With the demographic changes, the United States is becoming increasingly diverse and multicultural (U. S. Census Bureau, 2004). The concepts of cultural diversity and cultural competence are becoming common terms in the healthcare field, especially to nurses who represent the majority of the healthcare workforce. Cultural competence is closely related to the quality of care and is a cross-cutting issue affecting all healthcare systems. However, studies have shown that American nurses experienced a lack of cultural confidence and knowledge in caring for culturally diverse populations (Coffman, Shellman, \& Bernal, 2004; Hagman, 2006; Jones, Cason, \& Bond, 2004).

According to Institute of Medicine (2002), cultural competence affects healthcare outcomes; therefore, all healthcare providers should enhance their cultural awareness and competence through education to reduce health disparities. However, cultural competence is a process. According to St. Clair and McKenry (1999), "the development of cultural competence requires time, movement of individuals from stages of ethnocentrism, acquisition of cultural self-efficacy, and transformation in cultural perspectives that assists individuals in becoming ethnorelative" ( $p$. 229).

Nursing students, the future nursing workforce, need to be educated how to become culturally competent in providing care to diverse patients at the very beginning of their career training. Several professional associations and accrediting bodies have emphasized the importance of including cultural competence into nursing education in the past 20 years (American Academy of Nursing, 1992; American Association of Colleges of Nursing, 1998; ANA, as cited in Campinha- 
Bacote, 2006; Board of Registered Nursing of California, 2006). With such a strong emphasis on incorporating cultural competence in nursing education, there is a need to examine how confident today's nursing students are in providing care to diverse populations.

\section{Literature Review}

The concept of cultural competence was originally developed by Leininger (1978). In her theory of transcultural nursing, Leininger recognized the necessity of having nurses appreciate the racial and ethnic differences in the health practices of people from different ethnic groups. To date, cultural competence is considered as a process, not an end-point. It is more than the achievement of skills to work with people of different ethnic groups, including understanding their traditions, beliefs, customs, and values (St. Clair \& McKenry, 1999). Cultural competence also includes "effectively working with the cultural context of race; gender; and sexual orientation of the individual, family, or community" (Campinha-Bacote, Yahle, \& Langenkamp, 1996, p. 59).

In order to become culturally competent, it is imperative for healthcare providers to first develop a sense of cultural self-efficacy, which is defined as "the achievement of certain communication skills, cultural assessment skills, and cultural knowledge regarding health practices and traditions of varied cultures" (St. Clair \& McKenry, 1999, p. 229). Nurses with a higher level of cultural self-efficacy are more comfortable in working with diverse patients and more likely to increase their cultural competence in working with these patients as compared to nurses with a lower level of cultural self-efficacy because Bandura (1977) believes that selfefficacy can help people cope with the demands of a particular situation.

Several published studies examined nursing students' perceived cultural self-efficacy in providing care to diverse populations. Kulwicki and Boloink (1996) found that baccalaureate 
nursing students in Michigan had little or no confidence in providing care to culturally diverse clients as measured by Bernal and Froman's Cultural Self-Efficacy Scale (CSES). Bond, Kardong-Edgren, and Jones (2001) found that BSN students in Texas had a slightly higher level of confidence in understanding cultural concepts as compared to RN to BSN students and MSN students. However, all subjects in their study showed a relatively low knowledge base in cultural skills and cultural patterns of different cultural groups as measured by CSES. In a literature review of 26 studies that used CSES to measure nurses and nursing students' cultural selfefficacy, Coffman, Shellman, and Bernal (2004) reported that American nurses and nursing students perceived a lack of self-efficacy in caring for culturally diverse populations. They also found that exposures to cultural concepts and to ethnically diverse populations were positively associated with perceived cultural self-efficacy. Jimenz, Contreras, Shellman, and Bernal (2006) discovered that nursing students in Spain had a lower level of cultural self-efficacy than American correspondents while Spanish nurses had a higher level of cultural confidence than the corresponding American nurses as measured by CSES.

Other studies have evaluated the effect of cultural diversity related education and international immersion experience in the nursing program on undergraduate and graduate nursing students in the urban Arizona State, Northeastern public university, Australia, Midwestern county, New England, and Massachusetts (Alpers \& Zoucha, 1996; Jeffreys, 1999; Lim, Downie, \& Nathan, 2004; Napholz, 1999; St. Clair \& Mc Kenry, 1999; Williamson, Stecchi, Allen, \& Coppens, 1996). The results of these studies demonstrated that cultural education or cultural exposure could increase students' cultural self-efficacy or cultural competence skills. 
To date, no published studies were found to measure baccalaureate nursing students' cultural self-efficacy in the Silicon Valley of California, where the population is more culturally diverse as compared to national statistics. According to U.S. Census Bureau (2004), in the year 2000 , Whites accounted for $69.4 \%$ of the total population, followed by Blacks $(12.7 \%)$, Hispanics (12.6\%), and Asians (3.8\%). However, in the city of San Jose located in Silicon Valley in California, in the year 2000 Whites only accounted for $47.5 \%$ of the local population, followed by Hispanics (30.2\%), Asians (26.9\%), and Blacks (3.5\%)(U.S. Census Bureau, 2006). Cultural diversity in this local population can provide nursing students the opportunity for cultural encounters with patients from other ethnic groups to practice their culturally competent care. According to Campinha-Bacote (2002), cultural encounter is defined as "the process that encourages the health care providers to directly engage in cross-cultural interactions with clients from cultural diverse backgrounds" (p. 182). Cultural encounters can help healthcare providers prevent stereotyping when interacting with clients from culturally diverse groups and facilitate the process of cultural competence (Campihna-Bacote, 2002).

\section{Research Purpose}

The purposes of this study are (a) to examine the level of perceived cultural self-efficacy of graduating baccalaureate nursing students in a state funded university in the Silicon Valley in taking care of Black, Latino/Hispanic, and Asian populations at the last semester of their nursing program, and (b) to explore the relationship between baccalaureate nursing students' perceived level of cultural self-efficacy and their demographic responses.

The following three research questions guided the study:

1. What are the levels of perceived cultural self-efficacy of graduating baccalaureate nursing students in a state funded university in the Silicon Valley in providing cultural 
care for Black, Latino/Hispanic, and Southeast Asian populations as measured by Bernal and Froman's Cultural Self-Efficacy Scale (CSES)?

2. What is the difference among levels of perceived cultural self-efficacy of graduating baccalaureate nursing students in providing culturally specific care for Black, Latino/Hispanic, and Southeast Asian populations as measured by CSES?

3. What is the degree of the association between students' demographic data and their perceived level of cultural self-efficacy?

Conceptual Framework

\section{Bandura's Theory of Self-Efficacy}

Bandura's theory of self-efficacy (1977) was selected as the conceptual framework for this study. This theory is based on the belief that what people think, believe, and feel can affect their behavior. According to Bandura (1994), perceived self-efficacy is defined as "people's beliefs about their capabilities to produce designated levels of performance that exercise influence over events that affect their lives" (p. 71). People with higher self-efficacy would be more likely to interpret difficult tasks as challenges and to make extra efforts to complete the tasks than people with lower self-efficacy. People with higher self-efficacy would also be more likely to selfregulate their behaviors to meet their goals and objectives. Four sources can be used to enhance a person's self-efficacy beliefs and efficacy expectations: performance of the activity, vicarious experience, verbal persuasion, and person's physiological states (Bandura, 1977).

Four Sources of Self-Efficacy

Performance of the Activity.

The most effective and influential way of gaining self-efficacy is from mastering experiences (Bandura, 1977). Frequent successes in performing certain activities can enhance one's personal 
self-efficacy beliefs. In the process of cultural competence, nursing students frequently have the opportunities of being exposed to people from different ethnic groups in and outside the clinical settings. They can apply cultural knowledge and skills that they have acquired from their nursing schools to comfortably interact with these people. The students can also directly engage in the daily activities of these people to further understand their cultural norms, values, and health beliefs in order to increase their sense of self-efficacy or confidence in working with these people.

\section{Vicarious Experience.}

Vicarious experience through role models is the second source of gaining self-efficacy (Bandura, 1977). Watching other people with similar experiences succeed will help enhance people's own self-efficacy. By observing how their instructors, preceptors, and peers interact with the patients from different cultural backgrounds in a comfortable and confident way through understanding and applying cultural knowledge and skills, nursing students can reassess their level of confidence and try to improve it later.

\section{Social Persuasion.}

Social persuasion is the third source of increasing people's self-efficacy beliefs (Bandura, 1977). "You can do it," a simple persuasion from the instructors or preceptors, not only can help nursing students alleviate their level of anxiety in working with diverse patients in the clinical settings but also can positively affect students' perception of their capabilities of working with these patients in a successful way.

\section{Physiological States.}

People can judge their capabilities for certain tasks by assessing their level of physiological states, e.g., stress, pain, mood, or fatigue. If they have a higher level of physiological state, 
people may not be willing to perform certain tasks, which would further undermine their selfefficacy beliefs (Bandura, 1977). In the process of cultural competence, nursing students are frequently required to learn how to adjust their stress level or negative moods to increase their sense of self-efficacy.

Overall, nursing students are frequently affected by all these four sources in becoming culturally confident to provide care to diverse populations during the course of their study. Just like cultural competence, gaining self-efficacy is a process, not an end-point. Students can periodically assess or be assessed their level of self-efficacy in order to identify their further learning needs and effectively employ all four sources to become culturally confident and competent in providing care to diverse populations.

$$
\text { Method }
$$

\section{Research Design}

This study employed a non-experimental, cross-sectional research design with survey methodology. All volunteer graduating baccalaureate nursing students in their last semester of a California state funded university nursing program enrolled in spring 2007 semester were recruited as a convenient sample for this study. Permission to conduct the current study was approved by both the university IRB and School of Nursing of this university. The investigator visited the students' senior year theory class and administered Bernal and Froman's Cultural Self-Efficacy Scale and a researcher-developed demographic questionnaire.

\section{Instruments}

Cultural Self-Efficacy Scale (CSES).

Cultural Self-Efficacy Scale (CSES), a 26-item, 5-point likert scale, was initially designed to measure the perceived sense of self-efficacy of community health nurses in caring for culturally 
diverse clients based on Bandura's theory of self-efficacy (Bernal \& Froman, 1987). The CSES was further revised and tested in a second study for its reliability and validity (Bernal \& Froman, 1993). Since then, this scale has been widely used to measure other healthcare providers' cultural self-efficacy, including registered nurses in the hospital settings and nursing students (Alpers \& Zoucha, 1996; Hagman, 2006; Kulwicki \& Boloink, 1996; St. Clair \& McKenry, 1999). The 26 items of this scale are grouped in three subscales namely: (a) knowledge of cultural concepts, (b) Knowledge of cultural patterns of specific ethnic groups, and (c) skills in performing cultural care. Participants were asked to rate their perceptions of confidence about cultural knowledge, patterns, and skills in caring for three ethnic groups of patients: Blacks, Latino/Hispanics, and Southeast Asians. Self-efficacy ratings range from 1 (very little confidence) to 5 (quite a lot of confidence). Content validity of the scale was discussed in the original two studies (Bernal \& Froman, 1987; 1993). Cronbach Alpha or the internal consistency coefficient of the CSES ranged from 0.86 to 0.98 (Coffman, Shellman, \& Bernal, 2004).

\section{Demographic Questionnaire.}

An 8-item researcher-developed demographic questionnaire was the second instrument for this study. Students' age, gender, race/ethnicity, primary language, educational background, experience with an interpreter, experience in being raised outside the United States, and traveling experience were asked in the questionnaire.

\section{Subjects and Sampling}

The graduating baccalaureate nursing students enrolled in a research theory class in spring 2007 were invited to participate in this study on a voluntary basis. These students were in their last semester of their nursing program and almost ready to take their licensure exam. They have been exposed to a variety of patients from different cultural groups along with their program and 
have been taught a lot of concepts and knowledge related to cultural care based on the requirement of the Board of Registered Nursing of California.

\section{Data Analysis}

Fifty-seven surveys were distributed to volunteer participants, and 48 surveys were returned to the investigator. The response rate was $84 \%$. Among these 48 surveys, 5 were not completed and discarded from this study. Data from these 43 completed surveys were entered into SPSS statistical analysis program. Subjects' mean ratings of perceived cultural self-efficacy in providing cultural care including knowledge of cultural concepts and cultural skills and their standard deviations were calculated. Subjects' mean ratings of perceived cultural self-efficacy in providing culturally specific nursing care to Blacks, Latino/Hispanics, and Southeast Asians and their standard deviations were each individually analyzed. Analysis of Variance (ANOVA) was used to analyze the differences among these three mean ratings. An independent t-test was used to examine any associations between the mean ratings and the demographic responses. These demographics included gender, ethnicity, primary language, educational level, previous working experience with an interpreter, and traveling experience.

\section{Results}

In this sample of 43 , the average age of the subjects was $27(\mathrm{SD}=5.5)$. The majority of them were females $(n=36,83.7 \%)$, Asians $(n=30,69.8 \%)$, generic BSN students $(n=39,90.7 \%)$, and stated English as their primary language $(n=36,83.7 \%)$. Fourteen subjects $(32.6 \%)$ reported being raised outside the United States and 19 (44.2\%) had lived outside the United States. Fifteen subjects (35\%) reported having experiences working with an interpreter (see Table 1).

The subjects' self-efficacy ratings for all items ranged from 2.67 to 4.14 with an overall mean of $3.58(\mathrm{SD}=0.5)$. The overall mean self-efficacy rating of 3.58 was in between the rating of 3 , 
neutral or noncommittal rating of confidence, and the rating of 4 , moderate degree of confidence. Cronbach Alpha or the internal consistency coefficient of the Cultural Self-Efficacy Scale was 0.95 in this study.

Table 2 showed means and standard deviations of the CSES knowledge of cultural concepts subscale. The overall mean score for this subscale was $3.60(\mathrm{SD}=0.7)$. Students reported having the lowest confidence in differentiating between inter and intra cultural diversity and having the highest confidence in distinguishing between ethnocentrism and discrimination.

Table 3 displayed means and standard deviations of the CSES cultural skills subscale. The overall mean score for this subscale was $3.38(\mathrm{SD}=0.7)$. The range of mean scores for each individual item was from 3.14 to 4.02 . Students reported feeling most confident in entering an ethnically distinct community as compared to performing other skills in this subscale.

Table 4 showed means and standard deviations of the CSES knowledge of cultural patterns subscale. In this table the highest self-efficacy scores were found for the Southeast Asian group, with an overall mean rating of $3.84(\mathrm{SD}=0.8)$. The range of mean scores for this group was from 3.58 (Item \#7, utilization of health system) to 4.14 (Item 17, beliefs toward respect and authority). The lowest self-efficacy scores were found for the Black group, with an overall mean rating of $3.21(\mathrm{SD}=0.7)$. The range of mean scores for the Black group was from 2.67 (Item \#9, Utilization of traditional folk health practices) to 3.49 (Item \#5, Role differentiation). The mean self-efficacy ratings for the Latino/Hispanic group were in between those of the Black group and the Southeast Asian group, but closer to the Southeast Asian group, with an overall mean rating of $3.79(\mathrm{SD}=0.8)$. The highest self-efficacy rating for the Latino/Hispanic group was reported for Item \#4, knowledge of type of social support. The lowest self-efficacy rating was for Item \#13, knowledge of class structure. Test item analysis indicated the students reported the greatest 
degree of confidence in their knowledge of role differentiation across all three ethnic groups. No specific item was found to have the lowest self-efficacy score across all three groups.

One way ANOVA comparing overall mean self-efficacy ratings across three ethnic groups did not show a statistically significant difference even though the self-efficacy rating for the Southeast Asian group was the highest. Independent t-tests were also performed to compare group overall self-efficacy means between demographic responses. The only significant difference in the overall self-efficacy existed in gender. Male students had a statistically higher overall self-efficacy score than female students (Male students, $\mathrm{n}=7$, mean 3.94, $\mathrm{SD}=0.7$; Female students, $\mathrm{n}=36$, mean $3.52, \mathrm{SD}=0.44 ; \mathrm{t}=2.1, \mathrm{p}=0.04)$. No other significant differences were found across ethnicity, primary language, whether or not being a RN to BSN student, working with an interpreter before, and having experience of being raised outside or living outside the United States.

\section{Discussion}

The results of this study described the level of cultural confidence of graduating baccalaureate nursing students in a state funded university in the Silicon Valley in taking care of diverse populations. The self-efficacy rating was found the highest for the Southeast Asian group in this study, followed closely by the Latino/Hispanic group. No similar findings have been reported in previous studies. In comparison with other studies that used the CSES to measure nursing students' cultural self-efficacy in different regions of the United States (Aplers \& Zoucha; Bloink; Kulwicki \& Bolonik; Talley; Williamson, et al, as cited in Coffman, Shellman, \& Bernal, 2004), the mean cultural self-efficacy ratings in this study were found increased in the knowledge of cultural concepts subscale and in the knowledge of cultural patterns for both 
Southeast Asian group and Hispanic group, but decreased in the cultural skills subscale (see Table 5).

Many factors may contribute to the changes in subjects' self-efficacy ratings in this study, including the increased cultural diversity of the local demographics, increased diversity of the subjects' ethnic backgrounds, and increased emphasis on incorporating cultural competence into nursing curriculum from the Board of Registered Nursing and other professional associations. In this study, a large number of participants claimed themselves as Asians $(n=30,70 \%)$. A high percentage of Hispanics (30.2\%) and Asians (26.9\%) were also reported in the local demographics (U.S. Census Bureau, 2006). In addition, all subjects in this study reported that they both had experiences of working with patients from different ethnic groups in and outside their nursing school program. Some subjects in this study had experiences of being raised or living outside the United States. The exposure to subjects' own cultures and their surrounding culturally diverse communities had been confirmed to have positive impacts on subjects' cultural self-efficacy (Bernal \& Froman, 1993; Coffman, Shellman, \& Bernal, 2004; Jimenze, Contreras, Shellman, \& Bernal, 2006). The findings of this study also fit well with Bandura's self-efficacy theory in which exposure to the task, performance of the activity, and vicarious experience are effective sources of efficacy expectations (Bandura, 1977).

This study also tested to identify if there was any association between the subjects' demographics and their level of cultural self-efficacy. The only significant finding was that male students had a higher level of confidence than female participants. Similar findings were not reported in other studies. Whether or not male nursing students have special characteristics to influence their level of confidence in cultural care needs to be further explored. 


\section{Implications}

The results of this study have provided nurse educators an initial assessment of how confident the graduating baccalaureate nursing students were in providing care to diverse populations in the Silicon Valley. Although the subjects' overall self-efficacy rating in caring for diverse populations was higher in this study as compared to previous studies, there is still a need for continuous evaluation. The subjects of the study were found not confident in performing some cultural skills such as performing a 24 hour diet review and taking a life history. The subjects also reported the least confidence in understanding certain cultural concepts such as distinguishing between intra and inter cultural diversity. These findings may suggest nurse educators continue to incorporate cultural concepts and skills in their nursing curriculum to meet these students' learning needs.

This study also supported the validity and reliability of CSES. Nurse educators may use this valid tool to assess their nursing students' level of cultural confidence along the course of nursing program. This assessment would help enhance both the educators and nursing students' self-awareness of cultural confidence in order to formulate action plans to facilitate the process of cultural competence in caring for culturally diverse populations for nursing students.

\section{Limitations}

The convenience sample of participants and small geographic area are major limitations of this study. Thus, the results of this study can only be applied to the population studied and can not be generalized to other populations in the area. Further studies need to be conducted using a larger randomly selected sample. 


\section{Conclusion}

This study provided preliminary data using the CSES to assess the level of confidence in providing cultural care to diverse populations among a sample of graduating baccalaureate nursing students in a state funded university in Silicon Valley, California. The subjects' overall cultural self-efficacy rating was found higher in this study in comparison with previous studies which were conducted in less culturally diverse geographic areas (Aplers \& Zoucha; Bloink; Kulwicki \& Bolonik; Talley; Williamson, et al, as cited in Coffman, Shellman, \& Bernal, 2004). The increased level of confidence in this study may be related to several factors such as the increased diversity of the local populations, increased diversity of students' ethnic backgrounds, and increased emphasis on incorporating cultural competence into nursing curriculum from the Board of Registered Nursing and other professional associations. However, subjects in this study reported less confidence in performing certain cultural skills and differentiating certain cultural concepts. Nurse educators may utilize these research findings to incorporate cultural concepts and provide opportunities to develop cultural skills in nursing curriculum to meet nursing students' learning needs in providing culturally competent care. 


\section{References}

Alpers, R.R., \& Zoucha, R. (1996). Comparison of cultural competence and cultural confidence of senior nursing students in a private southern university [Electronic version]. Journal of Cultural Diversity, 3(1), 9-15.

American Academy of Nursing. (1992). AAN expert panel report on culturally competent nursing care. Nursing Outlook, 40, 277-283.

American Association of Colleges of Nursing. (1998). The essentials of Baccalaureate education for professional nursing practice. Washington DC: Author.

Bandura. A. (1977). Self-efficacy: Toward a unifying theory of behavioral change [Electronic version]. Psychology Review, 84, 191-215.

Bandura, A. (1994). Self-Efficacy. In V.S. Ramachaudran (Ed.) Encyclopedia of human behavior (Vol. 4, p. 71-81). New York: Academic Press. Retrieved March 18, 2005, from http://www.emory.edu/EDUCATION/mfp/BanEncy.html.

Bernal, H., \& Froman, R. (1987). The confidence of community health nurses in caring for ethnically diverse populations. IMAGE: Journal of Nursing Scholarship, 19, 201-203.

Bernal, H., \& Froman, R. (1993). Influences on the cultural self-efficacy of community health nurses. Journal of Transcultural Nursing, 4(2), 24-31.

Board of Registered Nursing. (2006). California nursing practice act with regulations and related statutes. Charlottesville: LexisNexis.

Bond, M. L., Kardong-Edgren, S., \& Jones, M. E. (2001). Assessment of professional nursing students knowledge and attitudes about patients of diverse cultures [Electronic version]. Journal of Professional Nursing, 17, 305-312. 
Campinha-Bacote, J. (2002). The process of cultural competence in the delivery of healthcare services: A model of care [Electronic version]. Journal of Transcultural Nursing, 13, 181-184.

Campihna-Bacote, J. (2006). Cultural competence in nursing curricula: How are we doing 20 years later? Journal of Nursing Education, 45, 243-244.

Campinha-Bacote, J., Yahle, T., \& Langenkamp, M. (1996). The challenge of cultural diversity for nurse educators. The Journal of Continuing Education in Nursing, 27(2), 59-64.

Coffman, M. J., Shellman, J., \& Bernal, H. (2004). An integrative review of American Nurses' perceived cultural self-efficacy [Electronic version]. Journal of Nursing Scholarship, 36, 180-185.

Hagman, L. W. (2006). Cultural self-efficacy of licensed registered nurses in New Mexico [Electronic version]. Journal of Cultural Diversity, 13,105-112.

Institute of Medicine. (2002). Unequal treatment: What healthcare providers need to know about racial and ethnic disparities in healthcare. Retrieved on October 1, 2006, from Http://www.iom.edu/object.file/Master/4/175/Disparitieshcproviders8pgFINAL. pdf

Jeffreys, M. R. (1999). Changes in students' transcultural self-efficacy perceptions following an integrated approach to culture care [Electronic version]. Journal of Transcultural Nursing, $5(2), 6-12$.

Jimenez, J., Contreras, J., Shellman, J., Gonzalez, M., \& Bernal, H. (2006). The level of cultural self-efficacy among a sample of Spanish nurses in Southern Spain. Journal of Transcultural Nursing, 17(2), 164-170.

Jones, M. E., Cason, C. L., \& Bond, M. L. (2004). Cultural attitudes, knowledge, and skills of a health workforce [Electronic version]. Journal of Transcultural Nursing, 15, 283-290. 
Kulwicki, A., \& Boloink, B. J. (1996). Assessment of level of comfort in providing multicultural nursing care by Baccalaureate nursing students [Electronic version]. Journal of Cultural Diversity, 3(2), 40-45.

Leininger, M. (1978). Transcultural nursing: Concepts, theories, and practices. New York: Wiley \& Sons.

Lim, J., Downie J., \& Nathan, P. (2004). Nursing students' self-efficacy in providing transcultural care [Electronic version]. Nurse Education Today, 24, 428-434.

Napholz, L. (1999). A comparison of self-reported cultural competency skills among two groups of nursing students: Implications for nursing education. Journal of Nursing Education, 38(2), 81-3. Retrieve on September 7, 2006, from The H.W. Wilson Company/WilsonWeb.

St. Clair, A., \& McKenry, L. (1999). Preparing culturally competent practitioners. Journal of Nursing Education, 38, 228-234. Retrieved on October 2, 2006, from The H.W. Wilson Company/WilsonWeb.

U.S. Census Bureau. (2004). Projected population of the United States, by race and Hispanic origin: 2000 to 2050. Retrieved September 10, 2006, from www.census.gov/ipc/www/usinterimproj/.

U. S. Census Bureau. (2006). State and County quickFacts. Retrieved on September 11, 2006, from Http:/quickfacts.census.gov/qfd/states/06/0668000.html.

Williamson, E., \& Stecchi, J. M., Allen, B. B., \& Coppens, N. M. (1996). Multiple experiences enhance nursing students' learning. Journal of Community Health Nursing, 13(2), 73-81. 
Table 1

Respondent's Demographic Responses

Number of Respondents Percentage of Respondents

$$
(n=43)
$$

Gender

Male

7

16.3

Female

36

83.7

Primary language

English

36

Other

7

16.3

Ethnic Groups

Asian/Pacific Islander

30

69.8

African American/Black

2

4.7

Alaskan/Native

0

0

Mexican American

4

9.3

Other Hispanics

1

2.3

White

3

7.0

Other

3

7.0

Student Type

Generic BSN

90.7

RN-BSN

4

9.3

Raised outside the United States

Yes

14

No

29

67.4 
Lived outside the United States

Yes

No

Worked with an interpreter

Yes

15

28
44.2

55.8

34.9

65.1 
Table 2

Results of CSES Subscale: Knowledge of Cultural Concepts

\begin{tabular}{llcc}
\hline \multicolumn{2}{l}{ Item Number } & Mean & SD \\
\hline 1 & Distinguishing between inter and intra cultural diversity & 2.88 & 1.0 \\
2 & Distinguishing between ethnocentrism and discrimination & 4.02 & 0.9 \\
3 & Distinguishing between ethnicity and culture & 3.91 & 0.8 \\
\hline Column Mean & & 3.60 &
\end{tabular}

Note. The range for cultural self-efficacy is $1-5$. The higher number means the more confidence. 
Table 3

Results of CSES Subscale: Skills

Item Number Item Description

Mean SD

\begin{tabular}{llll}
\hline 20 & Confidence in using an interpreter & 3.40 & 1.1 \\
21 & Confidence in entering an ethnically distinct community & 4.02 & 0.9 \\
22 & Confidence in advocacy & 3.74 & 0.9 \\
23 & Confidence in performing a 24 hour diet review & 3.14 & 1.3 \\
24 & Confidence in participant observation & 3.30 & 1.1 \\
25 & Confidence in taking a life history & 3.26 & 1.1 \\
26 & Confidence in developing a genogram & 3.49 & 1.2 \\
\hline Column Mean & & 3.38
\end{tabular}

Note. The range for cultural self-efficacy is $1-5$. The higher number means the more confidence. 
Table 4

Results of CSES Subscale: Knowledge of Cultural Patterns

\begin{tabular}{|c|c|c|c|c|c|c|c|c|}
\hline \multicolumn{2}{|c|}{ Item Number Item Description } & \multicolumn{2}{|c|}{ Black } & \multicolumn{2}{|c|}{ Latino/Hispanic } & \multicolumn{3}{|c|}{ Southeast Asian } \\
\hline & & M & SD & M & SD & $\mathbf{M}$ & $\mathrm{SD}$ & Row M \\
\hline 4 & Family organization & 3.23 & 0.9 & 3.88 & 0.9 & 4.07 & 1.0 & 3.73 \\
\hline 5 & Role Differentiation & 3.49 & 0.9 & 3.98 & 0.8 & 3.91 & 1.1 & 3.79 \\
\hline 6 & Child care practice & 3.16 & 0.8 & 3.86 & 0.9 & 3.74 & 1.1 & 3.59 \\
\hline 7 & Utilization of health system & 3.30 & 1.0 & 3.74 & 0.9 & 3.58 & 1.0 & 3.54 \\
\hline 8 & Types of social supports & 3.33 & 0.9 & 4.0 & 0.8 & 3.95 & 0.9 & 3.76 \\
\hline 9 & $\begin{array}{l}\text { Utilization of traditional } \\
\text { folk health practices }\end{array}$ & 2.67 & 1.1 & 3.67 & 1.1 & 3.72 & 1.1 & 3.35 \\
\hline 10 & Nutritional patterns & 3.40 & 0.9 & 3.88 & 1.0 & 3.81 & 1.1 & 3.70 \\
\hline 11 & Economic style of living & 3.47 & 0.8 & 3.74 & 1.0 & 3.79 & 1.0 & 3.67 \\
\hline 12 & Migration patterns & 2.98 & 1.2 & 3.84 & 0.9 & 3.60 & 1.1 & 3.47 \\
\hline 13 & Class structure & 3.07 & 0.8 & 3.53 & 1.0 & 3.67 & 0.9 & 3.42 \\
\hline 14 & Employment patterns & 3.14 & 1.0 & 3.70 & 1.0 & 3.72 & 1.0 & 3.53 \\
\hline 15 & Patterns of disease-illness & 3.47 & 1.0 & 3.72 & 1.0 & 3.74 & 1.0 & 3.64 \\
\hline 16 & Beliefs about health and illnes & s 3.14 & 0.9 & 3.67 & 1.0 & 3.88 & 1.0 & 3.56 \\
\hline 17 & $\begin{array}{l}\text { Beliefs toward respect and } \\
\text { authority }\end{array}$ & 3.33 & 0.9 & 3.77 & 0.9 & 4.14 & 0.9 & 3.74 \\
\hline 18 & Beliefs toward modesty & 2.98 & 0.9 & 3.72 & 1.0 & 4.09 & 1.0 & 3.60 \\
\hline 19 & Religious beliefs and patterns & 3.23 & 0.9 & 3.86 & 1.0 & 4.0 & 1.0 & 3.70 \\
\hline Colur & $\overline{\text { Mean }}$ & 3.21 & & 3.79 & & 3.84 & & 3.61 \\
\hline
\end{tabular}

Note. The range for cultural self-efficacy is $1-5$. The higher number means the more confidence. 
Table 5

Comparison of the Cultural Self-efficacy Level among Nursing Students in the Current Study and Previous Studies

\begin{tabular}{|c|c|c|c|c|c|c|c|c|c|c|}
\hline & \multicolumn{2}{|c|}{ Blacks } & \multicolumn{2}{|c|}{ Hispanic } & \multicolumn{2}{|c|}{ Asian } & \multicolumn{2}{|c|}{ Concepts $^{\mathrm{a}}$} & \multicolumn{2}{|c|}{ Skills $^{b}$} \\
\hline & Mean & $\mathrm{SD}$ & Mean & $\mathrm{SD}$ & Mean & $\mathrm{SD}$ & Mean & $\mathrm{SD}$ & Mean & $\mathrm{SD}$ \\
\hline Current Study $(n=43)$ & 3.21 & 0.7 & 3.79 & 0.8 & 3.84 & 0.8 & 3.60 & 0.7 & 3.38 & 0.7 \\
\hline \multicolumn{11}{|c|}{ In Coffman et al's study $(2004, n=620)$} \\
\hline Mean & 3.0 & 1.1 & 2.8 & 1.0 & 2.2 & 1.0 & 3.2 & 1.0 & 3.6 & 1.1 \\
\hline $\begin{array}{l}\text { Bloink } \\
\text { (in Midwest, 1992) }\end{array}$ & 2.7 & 1.3 & 2.5 & 1.2 & 1.9 & 1.1 & 2.7 & 1.2 & 3.1 & 1.3 \\
\hline $\begin{array}{l}\text { Aplers \& Zoucha } \\
\text { (in Arizona, 1996, } n=\end{array}$ & 6.3 & 1.1 & 3.3 & 1.0 & 2.5 & 1.1 & 3.5 & 0.9 & 4.1 & 0.9 \\
\hline $\begin{array}{l}\text { Kulwicki \&Bolonik } \\
\text { (in Michigan, 1996, n }\end{array}$ & $\begin{aligned} & 2.5 \\
= & 71)\end{aligned}$ & 1.3 & 2.6 & 1.1 & 2.3 & 0.7 & 3.0 & 1.1 & 3.4 & 1.1 \\
\hline $\begin{array}{l}\text { Williamson et al } \\
\text { (in Massachusetts, } 19\end{array}$ & $\begin{array}{l}2.8 \\
96, n=56\end{array}$ & 0.7 & 2.6 & 0.7 & 2.3 & 0.7 & 3.0 & 1.1 & 3.5 & 1.1 \\
\hline $\begin{array}{l}\text { Talley } \\
\text { (in Midwest, 2002, n= }\end{array}$ & $\begin{array}{l}3.5 \\
351)\end{array}$ & 1.1 & 3.2 & 1.2 & na & na & 3.6 & 1.0 & 3.6 & 1.1 \\
\hline
\end{tabular}

Note. The range for cultural self-efficacy is $1-5$. The higher number means the more confidence. ${ }^{a}$ Knowledge of Cultural Concepts.

${ }^{\mathrm{b}}$ Skills in performing cultural care. 